\title{
Correction to: On the use of hierarchical fuzzy inference systems (HFIS) in expert-based landslide susceptibility mapping: the central part of the Rif Mountains (Morocco)
}

\author{
B. C. Ozer ${ }^{1} \cdot$ B. Mutlu ${ }^{2} \cdot$ H. A. Nefeslioglu ${ }^{1} \cdot$ E. A. Sezer ${ }^{3} \cdot$ M. Rouai ${ }^{4} \cdot$ A. Dekayir $^{4} \cdot$ C. Gokceoglu ${ }^{1}$ (D)
}

Published online: 23 July 2019

(C) Springer-Verlag GmbH Germany, part of Springer Nature 2019

Correction to: Bulletin of Engineering Geology and the Environment (2019)

https://doi.org/10.1007/s10064-019-01548-5

The published version of this article unfortunately contained a mistake. Figure 1 was presented incorrectly in the original article. The correct Fig. 1 is presented here.

The online version of the original article can be found at https://doi.org/ 10.1007/s10064-019-01548-5

\footnotetext{
C. Gokceoglu

cgokce@hacettepe.edu.tr; candan.gokceoglu@gmail.com

1 Faculty of Engineering, Department of Geological Engineering, Hacettepe University, Ankara, Turkey

2 Faculty of Engineering, Department of Computer Engineering, Gazi University, Ankara, Turkey

3 Faculty of Engineering, Department of Computer Engineering, Hacettepe University, Ankara, Turkey

4 Faculty of Sciences, Department of Geology, Moulay Ismail University, Meknes, Morocco
} 
Fig. 1 The location map of the study area

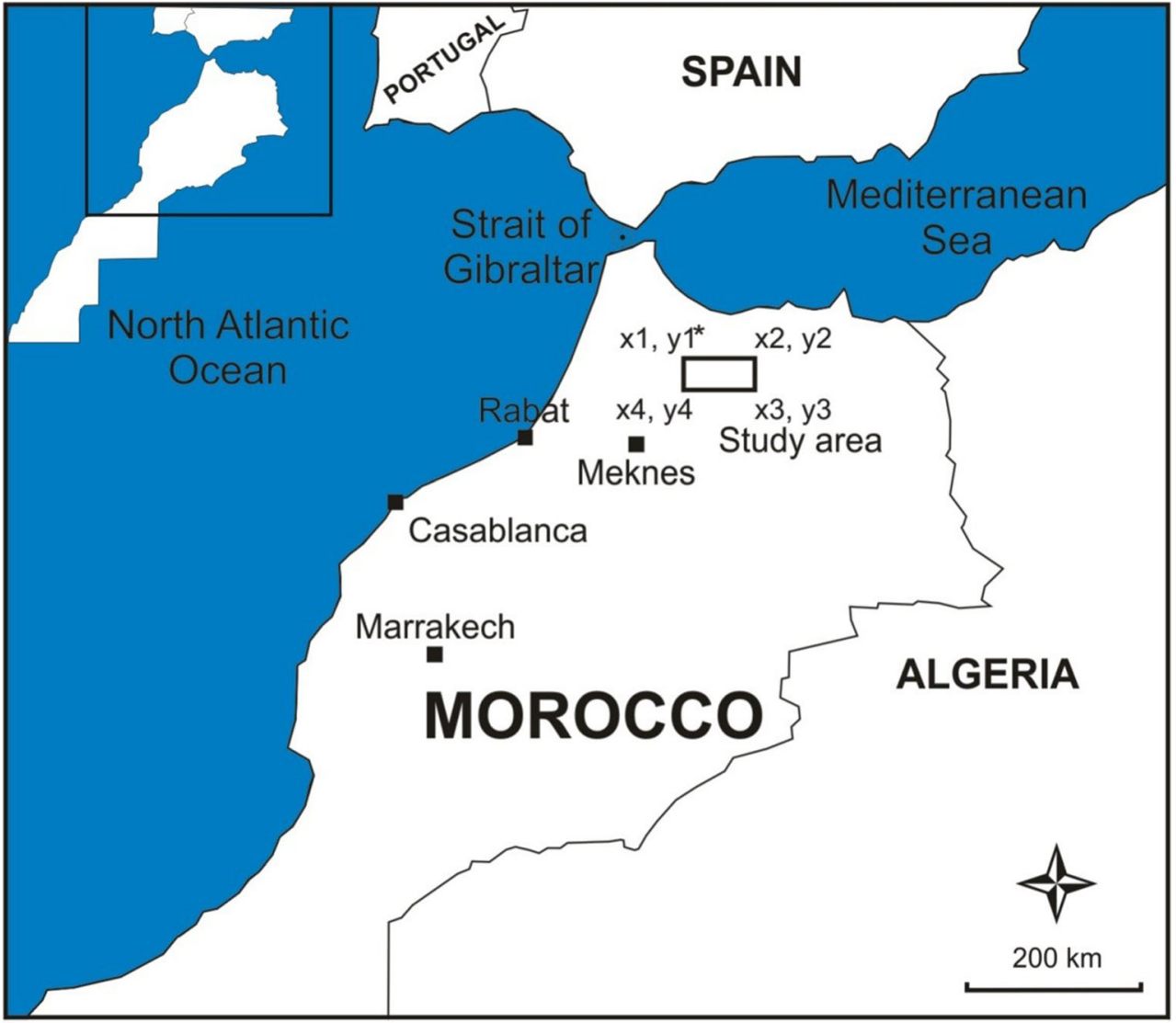

*x1, y1: 559521, 460967; x2, y2: 605296, 461352; x3, y3: 605601, 433648; $x 4$, y4: 559694, 433252; the coordinates are given in National Grid Africa; the Coordinate System Nord Maroc. 